\title{
Resposta de cultivares de trigo à infestação do pulgão Rhopalosiphum padi
}

\author{
Rafael Peruzzo(1), José Roberto Salvadori(2), Paulo Roberto Valle da Silva Pereira(2), Étel Carmen Bertollo(1) \\ e Lucas Simionatto Tonello(1)
}

\begin{abstract}
(1)Universidade de Passo Fundo, BR 285, Km 171, Bairro São José, CEP 99001-970 Passo Fundo, RS. E-mail: peruzzo11@yahoo.com.br, etelcb@yahoo.com.br, lucasstonello@yahoo.com.br (2)Embrapa Trigo, BR 285, Km 174, Caixa Postal 451, CEP $99001-970$ Passo Fundo, RS. E-mail: jrsalva@cnpt.embrapa.br, paulo@cnpt.embrapa.br
\end{abstract}

\begin{abstract}
Resumo - O objetivo deste trabalho foi avaliar a resposta de oito cultivares comerciais de trigo (BRS 194, BRS 208, BRS Camboatá, BRS Guabiju, BRS Guamirim, BRS Louro, BRS Timbaúva e BRS Umbu) à infestação do pulgão Rhopalosiphum padi (Hemiptera: Aphididae). O experimento foi realizado na Embrapa Trigo, em telado, em blocos ao acaso, com oito tratamentos e seis repetições, dispostos em parcelas subdivididas. As parcelas principais receberam os tratamentos com e sem infestação de pulgões, e as subparcelas foram compostas pelas cultivares. A infestação com os pulgões (20 adultos ápteros por planta) foi realizada aos 12 dias após a emergência das plantas, quando se encontravam no início do afilhamento, e foi mantida durante 15 dias. As cultivares avaliadas responderam diferentemente à infestação do pulgão R. padi. A cultivar BRS Timbaúva é a mais resistente, e as cultivares BRS Umbu e BRS Guabiju são as mais suscetíveis ao pulgão, quanto ao crescimento e a capacidade produtiva de plantas.
\end{abstract}

Termos para indexação: pulgão-da-aveia, resistência de plantas a insetos, tolerância de plantas.

\section{Wheat cultivars response to Rhopalosiphum padi infestation}

\begin{abstract}
The objective of this work was to evaluate the response of eight commercial wheat cultivars (BRS 194, BRS 208, BRS Camboatá, BRS Guabiju, BRS Guamirim, BRS Louro, BRS Timbaúva e BRS Umbu) to the infestation of Rhopalosiphum padi (Hemiptera: Aphididae). The experiment was carried out at Embrapa Trigo, in greenhouse conditions. It was used the randomized block design, in a split-plot array, with eight treatments and six replicates. The plots received treatments with or without infestation with aphids, and the split-plots were composed by the cultivars. The infestation with aphids ( 20 wingless adults per plant) was done 12 days after plant emergency, in the beginning of tillering, and was kept for 15 days. The cultivars responded differently to the infestation with aphids. BRS Timbaúva cultivar is more resistant, and BRS Umbu and BRS Guabiju cultivars are more susceptible to $R$. padi, concerning plant growth and plant yield.
\end{abstract}

Index terms: bird cherry-oat aphid, host plant resistance, plant tolerance.

\section{Introdução}

A cultura do trigo no Brasil é atacada por diversas espécies de pulgões, entre as quais Rhopalosiphum padi (Linnaeus, 1758) (Hemiptera: Aphididae), conhecido como pulgão-da-aveia ou pulgão-do-colmo, que tem apresentado elevado crescimento populacional, especialmente em lavouras da Região Sul (Salvadori \& Tonet, 2001). Os danos que os pulgões causam ao trigo podem ser diretos, decorrentes da sucção de seiva, ou indiretos, na condição de vetores da virose causada pelo
Barley yellow dwarf virus (BYDV) (Nass et al., 1998; Salvadori, 2000).

O controle químico, via tratamento de sementes ou pulverização da parte aérea com inseticidas, é comumente utilizado no combate a essa praga (Salvadori \& Salles, 2002; Silva et al., 2004). Contudo, além de onerar o custo de produção, o uso contínuo de inseticidas não seletivos apresenta riscos potenciais para operadores rurais, meio ambiente e organismos não visados (Salvadori et al., 2005). Dentro do enfoque de manejo integrado de pragas, seria importante a utilização de 
cultivares resistentes a pulgões, pois pode acarretar benefícios importantes tanto para o produtor, pela diminuição dos custos de produção, como para a sociedade, pela diminuição da contaminação do agroecossistema, além de oferecer maior segurança para as pessoas envolvidas com a aplicação de agrotóxicos (Salvadori \& Tonet, 2001; Salvadori et al., 2006).

De acordo com Painter (1951), a resistência de plantas a insetos pode se manifestar por meio da não-preferência - o inseto não escolhe a planta para alimento, abrigo e reprodução -; da antibiose - efeito negativo da planta na biologia do inseto -; e da tolerância - capacidade da planta de não sofrer danos, mesmo quando infestada pelo inseto. A não-preferência, como mecanismo de resistência de genótipos de trigo e de triticale ao pulgão R. padi, foi demonstrada por Hesler et al. (2002) e Hesler \& Tharp (2005), respectivamente. Hesler (2005) avaliou a alteração no crescimento de plântulas de trigo e triticale, infestadas por $R$. padi, e encontrou genótipos suscetíveis e genótipos tolerantes. A resistência do tipo antibiose a $R$. padi em trigo (genótipo MV4) foi registrada por Hesler et al. (1999), que consideram o seu uso como uma possível interação positiva com o controle biológico natural e com os inseticidas.

O objetivo deste trabalho foi avaliar a resposta de oito cultivares comerciais de trigo à infestação do pulgão R. padi.

\section{Material e Métodos}

O experimento foi conduzido em casa de vegetação, na sede da Embrapa Trigo, Passo Fundo, RS, de junho de 2006 a maio de 2007. Foram avaliadas as seguintes cultivares comercias de trigo: BRS 194, BRS 208, BRS Camboatá, BRS Guabiju, BRS Guamirim, BRS Louro, BRS Timbaúva e BRS Umbu, provenientes do programa de melhoramento genético da Embrapa, com expressiva área de cultivo no Sul do Brasil. As cultivares foram avaliadas quanto à resistência ao pulgão $R$. padi, isento de Barley yellow dwarf virus.

Os insetos utilizados provieram de criação mantida no Laboratório de Entomologia da Embrapa Trigo, a partir de indivíduos coletados em campo. Para a produção de insetos não virulíferos, ninfas recém paridas foram coletadas antes de tocar a planta hospedeira, e foram transferidas para plantas de trigo livres de vírus.

Utilizou-se o delineamento de blocos ao acaso, com parcelas subdivididas e seis repetições. Cada bloco foi dividido ao meio, no sentido longitudinal, o que deu origem às duas parcelas principais, com $4 \mathrm{~m}$ de comprimento por $0,9 \mathrm{~m}$ de largura, que receberam os tratamentos com e sem infestação de pulgões. Nos canteiros, as subparcelas espaçadas $0,2 \mathrm{~m}$ entre si foram constituídas pelas cultivares dispostas em linha transversal à parcela principal, de $0,9 \mathrm{~m}$ de comprimento, com 50 plantas cada. Toda a subparcela foi considerada como área útil $\left(0,18 \mathrm{~m}^{2}\right)$.

No dia 29 de junho de 2006, após a adubação do solo (250 $\mathrm{kg} \mathrm{ha}^{-1}$ da fórmula 5-25-25), foi realizada a semeadura na densidade de 80 sementes por $0,9 \mathrm{~m}$. As sementes utilizadas foram tratadas com o fungicida difeconazole a $15 \%$, na dose de $2 \mathrm{~mL} \mathrm{~kg}^{-1}$. Nas parcelas sem pulgões (não infestadas), além do tratamento com fungicidas as sementes também foram tratadas com inseticida imidacloprid $\left(1 \mathrm{~g} \mathrm{~kg}^{-1}\right)$. Após a emergência, realizou-se o desbaste para obtenção da densidade desejada (50 plantas por subparcela).

A infestação com os pulgões foi realizada aos 12 dias após a emergência, quando as plantas estavam com aproximadamente $15 \mathrm{~cm}$ de altura, correspondente ao estádio 2 (início do afilhamento) da escala de Feekes modificada (Large, 1954).

Para a realização da infestação, segmentos de folhas de trigo com o número de pulgões desejado (20 adultos ápteros por planta) foram cortados das plantas da criação. Em seguida, colocou-se um segmento em cada planta, e as parcelas, infestadas e não infestadas foram cobertas com uma gaiola de tecido do tipo "voill" $(4,5 \mathrm{~m}$ de comprimento x $0,5 \mathrm{~m}$ de altura $\times 1 \mathrm{~m}$ de largura), sustentado por arcos de ferro e fixado ao solo com a colocação de areia nas extremidades. A retirada das gaiolas ocorreu 15 dias após a infestação, quando toda $\mathrm{a}$ área experimental foi aspergida com inseticida à base de tiametoxam $\left(250 \mathrm{~g} \mathrm{ha}^{-1}\right)$.

As plantas foram conduzidas de acordo com as indicações técnicas para a cultura do trigo (Reunião da Comissão Sul-Brasileira de Pesquisa de Trigo, 2005). A adubação de cobertura foi realizada 35 dias após a emergência das plantas (afilhamento), tendose utilizado uréia como fonte de nitrogênio na dose de $40 \mathrm{~kg} \mathrm{ha}^{-1}$.

A colheita do experimento foi realizada entre 7 e 20 de novembro, de acordo com a maturação dos genótipos, os quais foram identificados e armazenados em uma sala para secagem. Antes da trilha, foram realizadas as seguintes avaliações: número de plantas, altura de planta, número de afilhos, número de espigas e massa de matéria 
seca (raiz e parte aérea das plantas). Após a trilha, foram determinados o peso de mil sementes, o número e o peso de grãos por subparcela.

Para todas as variáveis, foi calculada, em cada genótipo, a diferença relativa (\%) para os valores obtidos entre as plantas infestadas e não infestadas. Aos dados obtidos foi aplicada a análise de variância, seguida da comparação das médias pelo teste de Tukey, a 5\% de probabilidade, pelo SAS (SAS Institute, 2003). Aos dados de porcentagem foi aplicada a transformação angular arc sen $\%^{0,5}$, na análise de variância.

\section{Resultados e Discussão}

Constatou-se diferença estatisticamente significativa na resposta de cultivares à infestação de $R$. padi, em relação a número de plantas, de afilhos e de espigas. A população de pulgões que se desenvolveu a partir da infestação inicial atingiu níveis drásticos, que provocaram a morte de plantas e expressivas diferenças entre plantas infestadas e não infestadas de uma mesma cultivar.

A cultivar BRS Guabiju foi a que sofreu a maior mortalidade de plantas e diferiu estatisticamente das cultivares BRS Camboatá e BRS Louro (Tabela 1). A cultivar BRS Guamirim também apresentou maior número de plantas mortas, em relação às plantas não infestadas, quando comparada à cultivar BRS Louro, que não teve o número de plantas afetado pelos pulgões. Portanto, a cultivar BRS Louro foi mais resistente à alta infestação de $R$. padi do que as cultivares BRS Guabiju e BRS Guamirim. Os mecanismos de defesa exibidos pela planta, em resposta aos insetos, incluem uma série de características morfológicas e um complexo de substâncias químicas que tendem a tornar a planta repelente, tóxica ou de algum modo inadequada aos insetos (Vendramim \& Castiglioni, 2000).

As cultivares BRS Guabiju, BRS Guamirim e BRS Umbu sofreram maior redução no número de afilhos em comparação à cultivar BRS 194, como resultado da ação dos pulgões (Tabela 1). As demais cultivares ficaram em posição intermediária, entretanto a cultivar BRS Timbaúva também se destacou, por apresentar uma das menores diferenças relativas no número de afilhos nas plantas infestadas; mostrou-se menos suscetível que BRS Guabiju e não diferiu estatisticamente de BRS 194. Segundo Painter (1951), uma planta tolerante pode ter um menor prejuízo causado pelo inseto aos componentes do rendimento, de forma que não seja prejudicada sua produção. Provavelmente, isso ocorreu com as cultivares BRS 194 e BRS Timbaúva, que apresentaram menor diferença no número de afilhos em relação à cultivar BRS Guabiju. Redução do número de afilhos por planta pela ação de pulgões em trigo também foi observada por Tonet (1993), com a espécie de pulgão Schizaphis graminum, que constatou, ainda, resposta diferencial entre cultivares e linhagens de trigo submetidas à infestação de $S$ graminum, em termos de número de afilhos por planta.

Com relação à variável número de espigas, os resultados permitem destacar a cultivar BRS 194 como a que sofreu o menor impacto da infestação com $R$. padi (Tabela 1). Em situação oposta ficou a cultivar BRS Guabiju, com maior redução no número de espigas por unidade de área. Ainda em relação a esta variável, as

Tabela 1. Redução porcentual média, em cultivares de trigo, no número de plantas, de afilhos e de espigas, na altura de planta, na massa de matéria seca da parte aérea (MSa) e da raiz (MSr), no número de grãos e no peso de mil sementes (PMS) e de grãos, em plantas infestadas com o pulgão Rhopalosiphum padi, em relação a plantas não infestadas ${ }^{(1)}$.

\begin{tabular}{|c|c|c|c|c|c|c|c|c|c|}
\hline Cultivar & Plantas & Afilhos & Espigas & $\begin{array}{l}\text { Altura } \\
(\mathrm{cm})\end{array}$ & $\begin{array}{c}\mathrm{MSa} \\
(\mathrm{g})\end{array}$ & $\begin{array}{l}\mathrm{MSr} \\
(\mathrm{g})\end{array}$ & $\begin{array}{l}\text { Número } \\
\text { de grãos }\end{array}$ & $\begin{array}{l}\text { PMS } \\
(\mathrm{g})\end{array}$ & $\begin{array}{c}\text { Produção } \\
\text { de grãos (g) }\end{array}$ \\
\hline BRS 194 & $19,9 \mathrm{abc}$ & $27,2 \mathrm{c}$ & $27,5 \mathrm{c}$ & $25,0 \mathrm{bc}$ & $59,3 \mathrm{c}$ & $17,7 b$ & $55,6 \mathrm{~cd}$ & $21,6 \mathrm{ab}$ & $64,5 \mathrm{~cd}$ \\
\hline BRS 208 & $30,5 \mathrm{abc}$ & $33,6 a b c$ & $35,0 \mathrm{bc}$ & $26,6 \mathrm{bc}$ & $65,0 \mathrm{bc}$ & $44,5 \mathrm{ab}$ & $65,6 \mathrm{bc}$ & $21,8 \mathrm{ab}$ & $71,3 b c$ \\
\hline BRS Camboatá & $16,2 b c$ & $34,6 a b c$ & $35,5 b c$ & $24,8 \mathrm{bc}$ & $53,4 \mathrm{~cd}$ & $38,0 \mathrm{ab}$ & $56,0 \mathrm{~cd}$ & $20,6 a b$ & $63,5 \mathrm{~cd}$ \\
\hline BRS Guabiju & $38,4 \mathrm{a}$ & $49,1 \mathrm{a}$ & $51,1 \mathrm{a}$ & $33,4 \mathrm{ab}$ & $81,7 \mathrm{ab}$ & $56,0 \mathrm{a}$ & $82,6 \mathrm{ab}$ & $21,7 \mathrm{ab}$ & $85,3 \mathrm{ab}$ \\
\hline BRS Guamirim & $33,5 \mathrm{ab}$ & $45,4 \mathrm{ab}$ & $46,5 \mathrm{ab}$ & $25,0 \mathrm{bc}$ & $67,1 b c$ & $51,2 \mathrm{a}$ & $72,7 \mathrm{bc}$ & $8,6 \mathrm{~b}$ & $74,9 \mathrm{bc}$ \\
\hline BRS Louro & $0,0 \mathrm{c}$ & $36,5 \mathrm{abc}$ & $38,6 a b c$ & $27,6 \mathrm{bc}$ & $60,9 c$ & $41,4 \mathrm{ab}$ & $62,9 \mathrm{c}$ & $11,3 b$ & $65,6 c$ \\
\hline BRS Timbaúva & $24,8 \mathrm{abc}$ & $31,3 b c$ & $32,7 b c$ & $20,8 \mathrm{c}$ & $42,3 d$ & $32,6 \mathrm{ab}$ & $41,0 \mathrm{~d}$ & $16,0 \mathrm{ab}$ & $49,8 \mathrm{~d}$ \\
\hline BRS Umbu & $23,6 \mathrm{abc}$ & $43,5 \mathrm{ab}$ & $43,2 \mathrm{ab}$ & $41,6 \mathrm{a}$ & $90,8 \mathrm{a}$ & $49,2 \mathrm{a}$ & $94,7 \mathrm{a}$ & $31,7 \mathrm{a}$ & $96,1 \mathrm{a}$ \\
\hline Média & 24,9 & 37,6 & 38,7 & 28,1 & 65,0 & 41,3 & 66,3 & 19,1 & 71,3 \\
\hline CV $(\%)$ & 42,6 & 22,2 & 20,9 & 21,1 & 13,7 & 39,3 & 15,2 & 51,4 & 12,4 \\
\hline
\end{tabular}

${ }^{(1)}$ Médias seguidas por letras iguais, na coluna, não diferem entre si pelo teste de Tukey, a $5 \%$ de probabilidade. 
cultivares BRS 208, BRS Timbaúva e BRS Camboatá não diferiram estatisticamente de BRS 194 e se mostraram menos suscetíveis que BRS Guabiju. Esta suscetibilidade da cultivar BRS Guabiju pode estar associada a fatores ambientais, principalmente temperatura e radiação solar, que podem favorecer os níveis de resistência ou suscetibilidade da planta em relação ao inseto e afetar as interações entre estes dois organismos (Kogan \& Paxton, 1983).

Quanto ao crescimento das plantas, houve diferença estatisticamente significativa entre as cultivares quanto à altura de planta, massa de matéria seca da parte aérea e massa de matéria seca de raiz (Tabela 1).

A cultivar BRS Timbaúva foi a que apresentou a menor diferença relativa na altura das plantas infestadas em relação às não infestadas, tendo-se mostrado mais resistente em comparação às cultivares BRS Umbu e BRS Guabiju (Tabela 1). As cultivares BRS Louro, BRS 208, BRS Guamirim, BRS 194 e BRS Camboatá apresentaram melhor resposta de resistência que a cultivar BRS Umbu, pois sofreram, comparativamente, menor redução na altura de planta. Este resultado tem respaldo no trabalho de Hesler (2005) que, ao avaliar a resposta de genótipos trigo e triticale à infestação de $R$. padi, constatou diferenças quanto ao crescimento de plântulas.

As cultivares BRS Umbu e BRS Guabiju apresentaram maior redução na massa de matéria seca da parte aérea, em comparação às cultivares BRS Louro, BRS 194, BRS Camboatá e BRS Timbaúva. BRS Timbaúva foi menos afetada pela infestação de pulgões $R$. padi quanto ao crescimento da parte aérea, tendo-se mostrado mais resistente que BRS Umbu, BRS Guabiju, BRS 208, BRS Guamirim, BRS Louro e BRS 194; a cultivar BRS Camboatá não diferiu significativamente de BRS Timbaúva. Com relação à variável massa de matéria seca de raiz, a cultivar BRS 194 mostrou-se mais tolerante que as cultivares BRS Guabiju, BRS Guamirim e BRS Umbu, e as demais ficaram em posição intermediária (Tabela 1).

A cultivar BRS Timbaúva não se mostrou estatisticamente diferente das cultivares BRS Camboatá e BRS 194 quanto ao número de grãos, porém diferiu de todas as demais. BRS Timbaúva evidenciou menor sensibilidade à ação dos insetos, e BRS Umbu foi a cultivar mais afetada pela infestação quanto ao número de grãos produzidos (Tabela 1).
Para o peso de mil sementes (PMS), a cultivar BRS Umbu apresentou maior redução relativa, em comparação às cultivares BRS Guamirim e BRS Louro, mas não diferiu estatisticamente das demais cultivares (Tabela 1).

Com relação à variável produção de grãos, a maior diferença de resposta entre cultivares foi obtida na comparação entre BRS Timbaúva e BRS Umbu (Tabela 1). A menor perda no peso de grãos, observada na cultivar BRS Timbaúva, pode ser explicada pelo comportamento semelhante apresentado por esta cultivar na resposta à infestação de pulgões em termos de altura, massa de matéria seca da parte aérea das plantas e número de grãos produzidos por unidade de área.

A cultivar BRS Guabiju, apesar de não ter apresentado a maior diferença relativa no peso de grãos (Tabela 1), mostrou outras evidências de elevada suscetibilidade ao pulgão R. padi. Tonet \& Silva (1995) mostraram que $S$. graminum pode causar redução no número de espigas por planta e baixos rendimentos de grãos em cultivares de trigo. Este resultado está coerente com a resposta da BRS Guabiju à infestação de pulgões, que apresentou elevadas reduções de massa de matéria seca da parte aérea e raiz, número de planta, afilhos, espigas e grãos por subparcela.

Ao estudar os efeitos da infestação de $S$. graminum, $S$. avenae e $R$. padi sobre o trigo, no estádio de duas folhas, Kieckchefer \& Kantack (1980) concluíram que perdas de rendimento estiveram associadas a reduções no número de espigas, número de espiguetas, peso da espiga e peso de 100 grãos.

Considerando-se que todas as cultivares sofreram infestação elevada na fase de plântula e que, em todas as subparcelas, a população de pulgões evoluiu positivamente, é provável que as diferenças entre cultivares sejam resultantes, principalmente, do mecanismo de tolerância das plantas (Hesler, 2005). Não se pode, entretanto, descartar a existência de nãopreferência (Hesler et al., 2002) e de antibiose (Hesler et al., 1999).

\section{Conclusões}

1. As cultivares avaliadas respondem diferentemente à infestação do pulgão Rhopalosiphum padi.

2. A cultivar BRS Timbaúva é mais resistente, e as cultivares BRS Umbu e BRS Guabiju são mais suscetíveis ao pulgão $R$. padi, quanto ao crescimento e à capacidade produtiva de plantas. 


\section{Referências}

HESLER, L.S. Resistance to Rhopalosiphum padi (Homoptera: Aphididae) in three triticale accessions. Journal of Economic Entomology, v.98, p.603-610, 2005.

HESLER, L.S.; RIEDELL, W.E.; KIECKHEFER, R.W.; HALEY, S.D. Responses of Rhopalosiphum padi (Homoptera: Aphididae) on cereal aphid-resistant wheat accessions. Journal of Agricultural and Urban Entomology, v.19, p.133-140, 2002.

HESLER, L.S.; RIEDELL, W.E.; KIECKHEFER, R.W.; HALEY, S.D.; COLLINS, R.D. Resistance to Rhopalosiphum padi (Homoptera: Aphididae) in wheat germplasm accessions. Journal of Economic Entomology, v.92, p.1234-1238, 1999.

HESLER, L.S.; THARP, C. Antibiosis and antixenosis to Rhopalosiphum padi among triticale accessions. Euphytica, v.143, p.153-160, 2005.

KIECKHEFER, R.W.; KANTACK, B.H. Losses in yield in spring wheat in South Dakota caused by cereal aphids. Journal of Economic Entomology, v.73, p.582-585, 1980.

KOGAN, M.; PAXTON, J. Natural inducers of plant resistance to insect. In: HEDIN, P.A. (Ed.). Plant resistance to insects. Washington: American Chemical Society, 1983. p.153-171.

LARGE, E.C. Growth stages in cereals. Illustration of the Feekes scale. Plant Pathology, v.3, p.128-129, 1954.

NASS, P.H.; DOMIER, L.L.; JAKSTYS, B.P.; D'ARCY, C.J. In situ localization of Barley yellow dwarf virus-PAV $17-\mathrm{kDa}$ protein and nucleic acids in oats. Phytopathology, v.88, 10311039, 1998.

PAINTER, R.H. Insect resistance in crop plants. New York: MacMillan, 1951. 520p.

REUNIÃO DA COMISSÃO SUL-BRASILEIRA DE PESQUISA DE TRIGO, 37., 2005, Cruz Alta. Indicações técnicas da Comissão Sul-Brasileira de Pesquisa de Trigo: trigo e triticale - 2005. Cruz Alta: Comissão Sul-Brasileira de Pesquisa de Trigo, 2005. 162p.
SALVADORI, J. R. Pragas da lavoura de trigo. In: CUNHA, G.R.; BACALTCHUK, B. (Org.). Tecnologia para produzir trigo no Rio Grande do Sul. Porto Alegre: Assembléia Legislativa do Rio Grande do Sul, Comissão de Agricultura, Pecuária e Cooperativismo; Passo Fundo: Embrapa Trigo, 2000. p.267-287. (Série Culturas, 2).

SALVADORI, J.R.; PEREIRA, P.R.V.; SILVA, M.T.B. Manejo de pulgões. Revista Cultivar, v.75, p.32-34, 2005.

SALVADORI, J.R.; PEREIRA, P.R.V.; VOSS, M. Controle biológico de pragas do trigo. In: PINTO, A.S.; NAVA, D.E.; ROSSI, M.M.; MALERBO-SOUZA, D.T. (Org.). Controle biológico de pragas. Piracicaba: CP 2, 2006.

SALVADORI, J.R.; SALLES, L.A.B. de. Controle biológico dos pulgões do trigo. In: PARRA, J.R.P.; BOTELHO, P.S.M.; CORRÊAFERREIRA, B.S.; BENTO, J.M.S. (Org.). Controle biológico no Brasil: parasitóides e predadores. São Paulo: Manole, 2002. p.427447.

SALVADORI, J.R.; TONET, G.E.L. Manejo integrado dos pulgões de trigo. Passo Fundo: Embrapa-CNPT, 2001. (Documentos, 34).

SAS INSTITUTE. SAS 9.1.3 service pack3. Cary: SAS Institute, 2003.

SILVA, M.T.B.; COSTA, E.C.; BALARDIN, R.S. Reação de cultivares e eficiência do controle químico de pulgões vetores do Barley yellow dwarf virus em trigo. Ciência Rural, v.34, p.13331340, 2004.

TONET, G.L. Resistência de genótipos de trigo ao pulgão-verdedos-cereais Schizaphis graminum (Rondani, 1852) (Homoptera, Aphididae). 1993. 153p. Tese (Doutorado) - Universidade Federal do Rio Grande do Sul, Porto Alegre.

TONET, G.L.; SILVA, R.F.P. Resistência de genótipos de trigo ao biótipo C de Schizaphis graminum (Rondani, 1852) (Hom., Aphididae). Pesquisa Agropecuária Brasileira, v.30, p.1283-1287, 1995.

VENDRAMIM, J.D.; CASTIGLIONI, E. Aleloquímicos, resistência de plantas e plantas inseticidas. In: GUEDES, J.C.; COSTA, I.D.; CASTIGLIONI, E. (Org.). Bases e técnicas do manejo de insetos. Santa Maria: UFSM, 2000. p.113-128. 